\section{PTH-105 HOSPITAL ADMISSION IN PATIENTS WITH ADVANCED CHRONIC LIVER DISEASE DUE TO NON-ALCOHOLIC FATTY LIVER DISEASE}

${ }^{1}$ Jessica Shearer* ${ }^{1}$ Robert Driver, ${ }^{1}$ Eleanor Taylor, ${ }^{2}$ David Chizhande, ${ }^{1}$ Rebecca Jones, 1,3 lan Rowe. 'Leeds Liver Unit, Leeds Teaching Hospitals NHS Trust, Leeds, UK' ' Informatics Department, Leeds Teaching Hospitals NHS Trust, Leeds, UK; ${ }^{3}$ Leeds Institute for Data Analytics, University of Leeds, Leeds, UK

\subsection{6/gutjnl-2018-BSGAbstracts.261}

Introduction Individuals with non-alcoholic fatty liver disease (NAFLD) often have multiple medical comorbidities. The development of advanced chronic liver disease is considered a defining point in the natural history of NAFLD. The aims of this study were to pilot the use of electronic health record (EHR) follow-up of patients with NAFLD and to assess the frequency of clinical events due to both complications of liver disease and also non-liver related causes.

Methods Transient elastography data was collected from St James's University Hospital in Leeds between 2012-2017 Patients were defined as having advanced chronic liver disease based on liver stiffness measurement (LSM) $>10 \mathrm{kPa}$ and were analysed in two strata: $\geq 10-15 \mathrm{kPa}$, and $>15 \mathrm{kPa}$. Hospital admissions and mortality were recorded from data submitted to NHSDigital, and sub-divided into liver-related and nonliver related causes.

Results The study included 486 patients: 303 (62\%) male, mean age 56 years. Median follow-up interval was 24 months. Data regarding admissions is summarised in table 1. Four patients (all with LSM $>20 \mathrm{kPa}$ ) were admitted on eight occasions with decompensation as a primary diagnosis code (5 admissions with hepatic encephalopathy, 2 variceal bleeding and 1 ascites). Four patients had primary diagnosis codes for hepatocellular carcinoma. Overall, liver-related events accounted for a minority of admissions. Considering inpatient admissions, only 1 in 5 admissions were for complications of liver disease, even amongst those individuals with LSM $>15 \mathrm{kPa}$ (table 1). The most common causes of nonliver related admission according to ICD-10 code were gastrointestinal (14\%), cardiovascular (11\%), musculoskeletal (10\%) and respiratory (9\%). Overall $17 / 486$ individuals (3.5\%) had died ( 5 patients $\geq 10-15 \mathrm{kPa} ; 12$ patients $>15 \mathrm{kPa}$ ). Liver disease was listed as a contributing factor in a minority of cases $(5 / 17,29 \%)$.

\begin{tabular}{|c|c|c|}
\hline Admissions & $\begin{array}{l}\text { Patients } T E \geq 10-15 \mathrm{kPa} \text { LSM } \\
\mathrm{n}=252\end{array}$ & $\begin{array}{l}\text { Patients TE }>15 \mathrm{kPa} \text { LSM } \\
\mathrm{n}=234\end{array}$ \\
\hline $\begin{array}{l}\text { Type of } \\
\text { admission }\end{array}$ & Inpatient $\mathrm{n}=58$ & Inpatient $n=89$ \\
\hline Liver related & 8 & 18 \\
\hline Non-liver related & 50 & 71 \\
\hline
\end{tabular}

Conclusions EHR can be used to accurately define outcomes in patients with advanced chronic liver disease due to NAFLD. The finding that liver related morbidity and mortality accounts for only 1 in 5 clinical events for patients with NAFLD and advanced chronic liver disease will significantly reduce the effectiveness of novel therapeutics in development for this patient group.

\section{PTH-106 \\ PLASMA S100A8/A9: A NOVEL MECHANISTIC BIOMARKER IN INNATE IMMUNE ACTIVATION IN ACUTE-ON-CHRONIC LIVER FAILURE}

${ }^{1,2} \mathrm{~A}$ Singanayagam, ${ }^{1} \mathrm{R}$ Nathwani, ${ }^{1,2} \mathrm{E}$ Triantafyllou, ${ }^{2} \mathrm{VC}$ Patel, ${ }^{1} \mathrm{~A}$ Dhar, ${ }^{2} \mathrm{M}$ McPhail, ${ }^{2} \mathrm{C}$ Bernsmeier, ${ }^{2} \mathrm{~J}$ Wendon, ${ }^{1,2} \mathrm{CG}$ Antoniades. ${ }^{1}$ Imperial College London; ${ }^{2}$ King's College London

10.1136/gutjnl-2018-BSGAbstracts.262

Introduction Acute-on-chronic liver failure (ACLF) is driven by systemic inflammation but lacks reliable diagnostic or prognostic biomarkers. Circulating S100A8/A9 heterodimer (calprotectin) is secreted by activated myeloid cells to activate and propagate innate immune responses and organ dysfunction. This study aims to evaluate circulating levels of S100A8/A9 in ACLF and determine its effect on myeloid cell function.

Methods Plasma S100A8/A9 concentration of 92 patients at admission was analysed using enzyme-linked immunosorbent assay (ELISA) in ACLF $(n=62)$, cirrhosis without organ failure $(\mathrm{n}=28)$ and healthy control $(\mathrm{n}=30)$ groups. Baseline plasma cytokines were measured by multiplex immunoassay. Indices of disease severity and survival was evaluated with Kaplan Meier analysis. Phenotype (CD11b, HLA-DR, Mer tyrosine kinase [MerTK], CD163 and CD206) of healthy CD14 +monocytes cultured with S100A8/A9 in vitro for 24 hours at 0,1000 and $2500 \mathrm{ng} / \mathrm{ml}$ was assessed using flow cytometry $(\mathrm{n}=6)$.

Results Admission plasma S100A8/A9 was higher in ACLF (median $2000 \mathrm{ng} / \mathrm{ml}$ ) compared with cirrhotics without organ failure $(934.8 \mathrm{ng} / \mathrm{ml} \mathrm{p}=0.007)$ and healthy control $(963 \mathrm{ng} / \mathrm{ml}$ $\mathrm{p}=0.003$ ) (figure 1). S100A8/A9 was higher in patients with systemic inflammatory response syndrome (SIRS) $(\mathrm{p}=0.045)$ and non-survivors $(p=0.01)$. Baseline interleukin-1 $\beta$ (IL-1 $\beta$ ) was elevated in ACLF compared to healthy $(0.07$ vs. $0.36 \mathrm{pg} / \mathrm{ml}$ $\mathrm{p}=0.009)$, correlating with $\mathrm{S} 100 \mathrm{~A} 8 / \mathrm{A} 9$ concentration $(\mathrm{r}=0.508$ $\mathrm{p}=0.01)$. Area under the receiver operating characteristic curve (AUROC) for S100A8/A9 to detect the presence of ACLF was $0.681(\mathrm{p}=0.009)$. For 90 day mortality in ACLF, AUROC was $0.694(p=0.014)$ but highest for the CLIF-ACLF score $(0.767$, $\mathrm{p}=0.001$ ). S100A8/A9 $>1406 \mathrm{ng} / \mathrm{ml}$ (sensitivity 0.73 specificity 0.61 ) was associated with decreased transplant-free survival (log rank $\mathrm{p}=0.02$ ) (figure 2). S100A8/A9 predicted 90 day mortality $(p=0.018)$ on univariate analysis, remaining significant in a multivariate logistic regression model (OR $1.0 \mathrm{p}=0.04$ ). In flow cytometric analysis, activated CD11b + HLA-DR ${ }^{\text {high }} \mathrm{MerTK}^{\text {low }}$ myeloid cells $(\%)$ significantly increased ( $p=0.01$, Friedman's ANOVA) as S100A8/A9 concentration increased from 1000 to $2500 \mathrm{ng} / \mathrm{ml}$ with a trend to reduction in CD206 $(p=0.13)$ (figure 3).

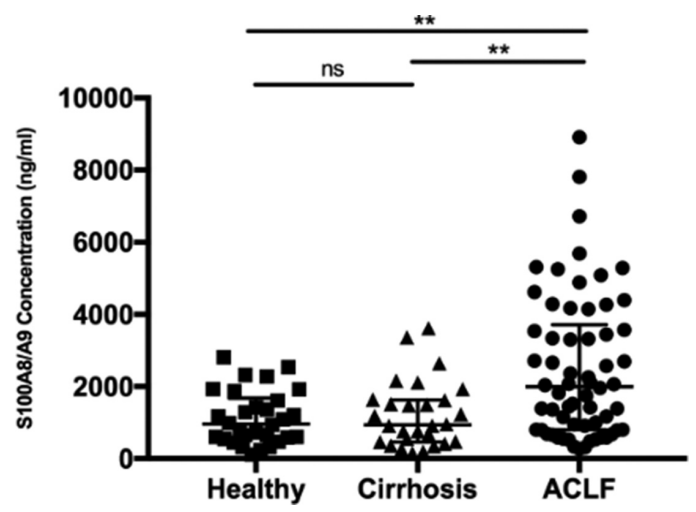

Abstract PTH-106 Figure 1 


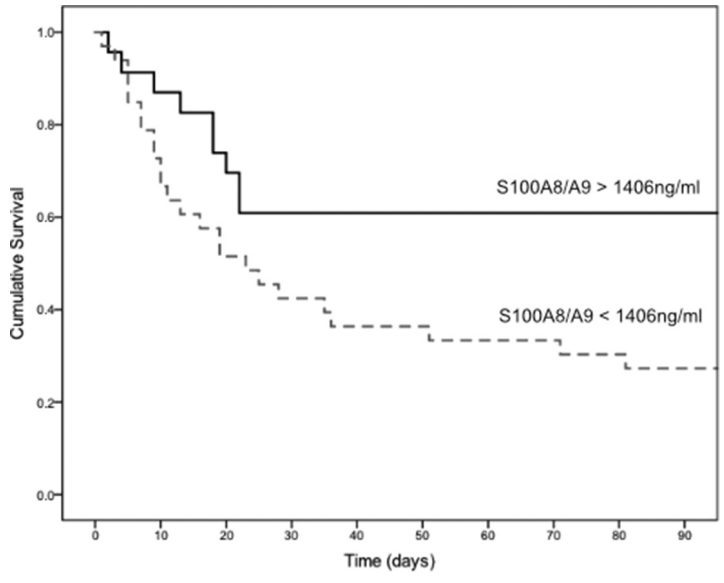

Abstract PTH-106 Figure 2

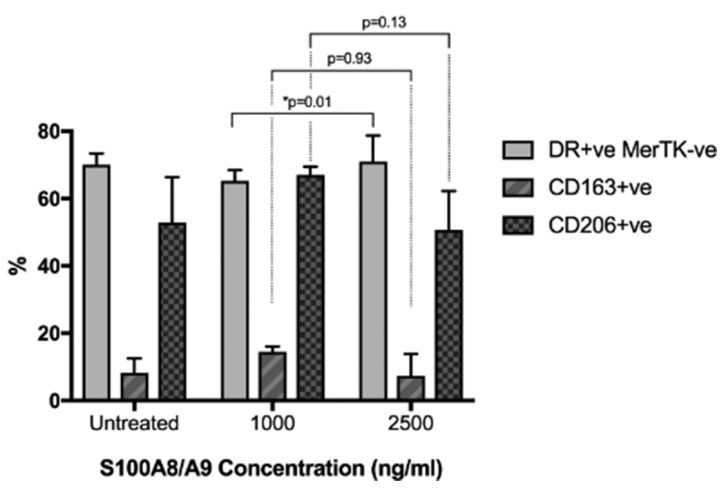

Abstract PTH-106 Figure 3

Conclusions Plasma S100A8/A9 is significantly elevated in ACLF, correlating strongly with activation of pro-inflammatory mediators and indices of disease severity, extra-hepatic organ failure and outcome. Our in vitro data indicate that this mediator promotes inflammation and represents a novel therapeutic target in ACLF.

\section{PTH-107 CORRELATION BETWEEN NON-INVASIVE TESTS AND DIFFERENT STAGES OF LIVER FIBROSIS IN PATIENTS WITH NAFLD}

W Siu* , I Ko, W Taj-Aldeen, A Mukhopadhya. Department of Digestive Disorders, Aberdeen Royal Infirmary, Aberdeen, UK

\subsection{6/gutjnl-2018-BSGAbstracts.263}

Introduction Non-alcoholic fatty liver disease (NAFLD) has become a major public health issue with an increasing prevalence worldwide. Accurate diagnosis and staging of the disease is important in determining the long-term management and follow-up of these patients. The aim of our study is to investigate the correlation between non-invasive tests and different stages of liver fibrosis in NAFLD.

Methods 905 patients with NAFLD underwent Fibroscan at Aberdeen Royal Infirmary from March 2013 to November 2016. 417 patients with liver stiffness measurement $>7 \mathrm{kPa}$ underwent electronic medical record reviews to identify patients who had liver biopsies within a year from the date of their Fibroscan. 54 out of 417 patients underwent liver biopsies. 42 of the 54 patients were identified to have biopsy-proven NAFLD. The histological reports of the liver biopsies were reviewed and different stages of fibrosis were recorded. Liver fibrosis was classified as no fibrosis (F0), mild fibrosis (F1), moderate fibrosis (F2), severe/bridging fibrosis (F3) and cirrhosis (F4). Clinical, radiological and biochemical data of these patients were also analysed, provided they were within 1 year from the dates of liver biopsies.

Results Out of the 42 patients identified, the mean age was $56( \pm 14)$ with a male preponderance $(55 \%) .1$ patient had no fibrosis (F0), 14 patients had mild fibrosis (F1), 1 patient had moderate fibrosis (F2), 14 patients had severe fibrosis (F3) and 12 patients had cirrhosis (F4). Correlation between different variables and stages of fibrosis were tested using the nonparametric Spearman's correlation coefficient. Data are summarised in the table 1 below and are expressed as median $\pm \mathrm{IQR}$.

\begin{tabular}{|c|c|c|c|c|}
\hline \multirow[b]{2}{*}{ Variable } & \multicolumn{3}{|c|}{ Fibrosis Stage } & \multirow{2}{*}{$\begin{array}{l}\text { Correlation Coefficient } \\
\text { (p- Value) }\end{array}$} \\
\hline & $\begin{array}{l}\mathrm{F} 0-\mathrm{F} 1 \\
(\mathrm{n}=15)\end{array}$ & $\begin{array}{l}F 2-F 3 \\
(n=15)\end{array}$ & $\begin{array}{l}F 4 \\
(n=12)\end{array}$ & \\
\hline $\begin{array}{l}\text { Liver stiffness measurement } \\
\text { (LSM) } \mathrm{kPa}\end{array}$ & $\begin{array}{l}10.1 \\
( \pm 5.8)\end{array}$ & $\begin{array}{l}21.3 \\
( \pm 5.5)\end{array}$ & $\begin{array}{l}33.3 \\
( \pm 13.7)\end{array}$ & $<0.001$ \\
\hline NAFLD Score & $\begin{array}{l}-0.64 \\
( \pm 2.67)\end{array}$ & $\begin{array}{l}0.28 \\
( \pm 1.65)\end{array}$ & $\begin{array}{l}0.83 \\
( \pm 1.01)\end{array}$ & $<0.001$ \\
\hline APRI Score & $\begin{array}{l}0.6 \\
( \pm 0.13)\end{array}$ & $\begin{array}{l}1.13 \\
( \pm 0.67)\end{array}$ & $\begin{array}{l}0.99 \\
( \pm 0.71)\end{array}$ & 0.212 \\
\hline Fibrosis-4 Score & $\begin{array}{l}1.26 \\
( \pm 1.84)\end{array}$ & $\begin{array}{l}2.66 \\
( \pm 2.14)\end{array}$ & $\begin{array}{l}3.04 \\
( \pm 5.69)\end{array}$ & 0.002 \\
\hline UKELD Score & $46( \pm 2.5)$ & $47( \pm 2)$ & $\begin{array}{l}47.5 \\
( \pm 3.25)\end{array}$ & 0.422 \\
\hline
\end{tabular}

Conclusions Our study indicated that there were statistically significant positive correlations between LSM, NALFD score and FIB-4 score with different stages of fibrosis in patients with NAFLD. However, the correlations between AST to Platelet Ratio Index (APRI), United Kingdom Model for EndStage Liver Disease (UKELD) score and different stages of fibrosis were not statistically significant. The difference may be due to the inclusion of clinical variables in the NAFLD score. The addition of LSM to the NAFLD score could potentially improve the diagnostic accuracy of fibrosis in NAFLD patients.

\section{PTH-108 THE OUTCOME OF TRANSARTERIAL CHEMOEMBOLIZATION FOR LIVER CANCER PATIENTS IN ABERDEEN ROYAL INFIRMARY}

Wamedh Taj-aldeen*, Sajith Kattiparambil, Fiona Clegg, Wilson Siu, Amalraj Raja, Lokesh Saraswat, Jack Straiton, Vijayan Balasubramaniam, Andrew Fraser, Lindsey Mcleman, Ashis Mukhopadhya. Aberdeen Royal Infirmary, Aberdeen, UK

\subsection{6/gutjnl-2018-BSGAbstracts.264}

Introduction Hepatocellular carcinoma (HCC) is the 5th most common cancer worldwide, it often presents in advanced stages with limited treatment options, reflected in its poor prognosis. Transarterial chemoembolisation (TACE) is an 